\title{
Strategic Management of Coal Mining Industry Efficiency
}

\author{
Olga Tkacheva ${ }^{1}$, Anna Batashova $^{1}$, Irina Zhukova ${ }^{1}$, Anna Smakhtina $^{1} \&$ Liudmila Topchienko $^{1}$ \\ ${ }^{1}$ The Shakhty Branch of M.I. Platov South-Russia State Polytechnic University (NPI), Shakhty, Russian \\ Federation \\ Correspondence: Anna Batashova, The Shakhty Branch of M.I. Platov South-Russia State Polytechnic \\ University (NPI), Russian Federation. Tel: 79-18-508-5375. E-mail: rusbatashova@yandex.ru
}

Received: April 9, 2015 Accepted: May 22, 2015 Online Published: July 15, 2015

doi:10.5539/ass.v11n20p104 URL: http://dx.doi.org/10.5539/ass.v11n20p104

\begin{abstract}
The purpose of this study is to develop recommendations for the coal mining industry efficiency strategic management. The authors developed a mathematical economic models to maximize the net present value of the index of companies in the composition of the coal mining industry and calculated the efficiency of Russian enterprises in the composition of the coal mining industry in Russia in 2013 using MathCad. The authors identified the main problems of coal mines and in the quality of their solutions offer an innovative approach to strategic management of the industry of the country, which includes: establishing a common standard in the monitoring, analysis and evaluation of the situation, management decision-making at all levels of corporate and public governance; elimination of dogmatism in the organization of corporate and public governance, encouraging maximum independence and initiative of corporate management in the framework of national development strategies; Schooling management training to all levels of management autonomy, rapid, and therefore efficient and effective management within the company's strategy; creation of a unified and transparent system of monitoring of management decisions and increase the level of responsibility of managers at all levels and branches of government for the implementation of the national strategy, and within it is a strategy of smaller entities. The result of the joint implementation of the proposed principles in the organization of strategic management at different levels of management should be a combination of freedom in solving economic problems and personal initiative managers.
\end{abstract}

Keywords: coal mining industry, efficiency, "personal factor", "strategic engagement", strategic management

\section{Introduction}

The need for a permanent improvement of quality management of business processes that determine the structure and functional areas of modern production management defined by the increased requirements of the competitive environment, increased competition with multinational corporations in the domestic market, followed by the national adaptation techniques and tools of strategic management in Russian economic conditions, the increasing number of factors, adversely affecting the normal course of the reproduction process, the changing role and status of enterprises in the national economy and giving them the status of the main component of sustainable growth of competitiveness and welfare of the Russian nation.

The urgency of modernization of industrial management of the country has been repeatedly emphasized in the President of the Russian Federation Federal Assembly, the need for such modernization aimed at increasing the effectiveness of strategic management across the sectors and industries of the national economy has long recognized as a separate system of public administration sectors, industries and industrial complexes of the country and by the industry. Expanding the scope of strategic management, the introduction of new teaching and methodological approaches to the organization of production using the principles of strategy and complexity will increase the efficiency of target complex programs with significant economic value, provide high-quality production processes, review, implementation and monitoring of management decisions in terms of the complex regard to their relevance and possible consequences, ultimately is a positive impact on the final results of industrial enterprises by improving the accuracy and validity, and thus increase the positive and reduce the negative impacts of management decisions. 


\section{Materials and Method}

Russia remains one of the world leaders in the production of coal. In its interior focused one-third of the world's coal resources (173 billion) and one fifth of proven reserves. Steam coal reserves account for about $80 \%$. Industrial stocks of existing enterprises make up almost 19 billion. Tons, including coking coal - about 4 billion tons.

According to the draft, "General scheme of the power facilities up to 2020" provides for the growth of electricity consumption in Russia by 2015 to a level of 1.426 trillion. KWh (1600 kWh high variant). The increase in 1,4-1 6 times.

Provides for the modernization of the electricity sector, including through the replacement of obsolete generating equipment for new modern samples with an average efficiency of coal-fired power plants by 2020 at least $38 \%$, and by 2030 - not less than $41 \%$, which implies a need to increase production and improve competitiveness of coal mining enterprises.

The fundamental principles of measuring enterprise competitiveness are to assess the value of the business. Improving the competitiveness of coal enterprises in the current market environment requires proper management of the property complex. Effective management of the property complex of the coal industry should provide increasing their attractiveness.

Due to the fact that the company is the subject of the sale, mortgage, lease and other transactions, it is characterized by the properties of the goods for which the market can get different prices depending on the ratio of demand, supply and quality of the goods. When placing the goods on the market, the company owner is going to get the maximum price based on its qualitative characteristics, which are determined primarily by increasing or stable profit margin in the reporting period and the position of the company on the market. Stable or increasing the profit margin, in turn, depends on the size of the cost of products manufactured by the company.

One method of business valuation is the income approach. Business Valuation according to the income method is based on a calculation of the net present value as the sum of the discounted cash flows for all periods forecasting and capitalized cash flow post-forecast period.

Factors of economic growth of the company may include the following components: profits from production, investment and financial activities on by-individual enterprises; cash flow, due to the increase in sales of products; the rate of turnover of working capital; improving the competitiveness of enterprises. In this case, the company has the ability to control a long-term plan of development of individual businesses to maximize the value of the industry as a whole.

Coal mining industry needed radical modernization, investment demand for the entire life cycle of the enterprise, therefore seeks to encourage investment projects related to the technical re-equipment, reconstruction, maintenance capacity of the existing coal-mining organizations.

In the Guidelines for assessing the effectiveness of investment projects, one of the accepted notions of equal NPV - Net Present Value. In this regard, the investment attractiveness of the coal mining company can be characterized by the "net present value of the enterprise" (HTCP), determining the economic growth of the business. Therefore, one of the factors of effective property management is to improve the mining company HTCP.

Maximization of the net present value of the company (CHTTSP) may be provided on the basis of the developed economic and mathematical model that allows while maintaining the planned volume of production to carry out a partial or complete retooling of the company to increase its economic potential. Economic-mathematical model to maximize the net present value of the index of companies as part of the coal mining industry is as follows:

$$
\begin{gathered}
H T C P=\left\{\sum_{t=1}^{T}\left[\sum_{i=1}^{N} P_{i t}-\sum_{t=1}^{N} C_{c p t} * g_{i t}-H_{u m t}\right]-n_{p}\left[\sum_{i=1}^{N} P_{i t}-\sum_{i=1}^{N} C_{p t} * g_{i t}-H_{u m t}\right]+\sum_{i=1}^{N} A_{i t}-\right. \\
\left.\sum_{i=1}^{N} K_{i t}\right\} * \frac{1}{(1+E)^{t}} \longrightarrow \text { max },
\end{gathered}
$$

Where

$$
C_{c p t}=C_{c r b} * \varepsilon_{i} * \frac{a_{i} * \frac{x_{i b}}{x_{i t}} * k^{*}+b_{i}}{\frac{x_{i b}}{x_{i t}} * k^{*}} * u * x_{i t},
$$

$\mathrm{N}$ is number of enterprises within the company, $\mathrm{i} € \mathrm{~N}$;

Pit are sales volume i-th coal-mining enterprise in the t-th year; 
Ccpt is the average cost per unit of output issue for the industry as a whole in the t-th year; git, gib is volume of output $\mathrm{i}$-th coal business in the $\mathrm{t}$-th and the base year, respectively;

Humt is property tax;

Ait is amount of depreciation of $\mathrm{i}$-coal business in the $\mathrm{t}$-th year;

np is income tax rate;

Kit is the value of capital investments $i$-th coal business in the $t$-th year;

Ccrb is average cost per unit of output for the release of a whole industry in the base period;

$\mathcal{E} \mathrm{i}$ is the ratio of the cost of issuance per unit of output for individual enterprises in the base period to the average cost of production for the industry as a whole;

ai is the proportion of variable costs in the cost of the individual enterprise of the reference period;

bi is the proportion of fixed costs in the cost base period ( $a$. and b. for all mines are taken constant in the period under review, equal to 0.5 );

xib, xit are the share of output for individual enterprises in the total volume of output in the base and the t-th year, respectively;

$\mathrm{k} *$ is coefficient of variation in output for the whole company in the t-th year, which is calculated by the following formula:

$$
k^{*}=\frac{\sum_{i=1}^{N} g_{i t}}{\sum_{i=1}^{N} g_{i b}},
$$

where $\mathrm{u}$ is the growth rate of production costs, taking into account the inflation process (taken in the reporting period equal to 1.07);

$\mathrm{T}$ is calculated (considered) a period sufficient to partially or completely re enterprise companies.

Reduced economic and mathematical model can be used to estimate the value of the coal mining company that generates cash flow from operating activities of its constituent individual enterprises. The implementation of economic-mathematical model of formation of business value, taking into account growth factors allows for uniform development of all businesses within the company through the implementation of timely technical re-equipment, without compromising the overall efficiency of production in the industry as a whole.

The development strategy of complex organizational and production systems, including in the coal industry, must comply with the trajectory behavior of enterprises. Require rapid development and updating of the construction and reconstruction of enterprises, as well as projects change management and organizational structure of flexible geotechnical mining complexes and energy companies.

\section{Results}

Economic-mathematical model to maximize the net present value of the index of Russian companies in the composition of the coal mining industry in Russia in 2013, calculated using MathCad, is as follows:

$$
\begin{gathered}
\mathrm{HTCP}=\left\{\sum_{t=1}^{T}\left[\sum_{i=1}^{228} P_{i t}-\sum_{t=1}^{228} C_{c p t} * g_{i t}-2,2\right]-n_{p}\left[\sum_{i=1}^{228} P_{i t}-\sum_{i=1}^{228} C_{p t} * g_{i t}-2,2\right]+\sum_{i=1}^{228} A_{i t}-\sum_{i=1}^{228} K_{i t}\right\} * \\
\frac{1}{(1+1,25)^{t}}=80591 \text { million dollars. }
\end{gathered}
$$

This is quite low compared other countries, given that the Russian coal industry has 228 enterprises. It is therefore necessary to improve strategic management of the branch efficiency Russian coal industry. Among the main problems of the development of coal mines are the following (Popkova, Tinyakova, 2013a):

1. Difficulties in attracting long-term investments for renew existing facilities and construction of new coal industry.

2. The high proportion of costs (30\%) accounted for the construction of new facilities.

3. Insufficient supply of industrial workers and personnel during construction and subsequent operation of coal enterprises.

4. High level of deterioration of the equipment of enterprises.

5. Distance stores, the complexity of the transport chain in the sale of products. 
6. Low wages, high part of it (30-40\%) in the structure of production costs.

In recent years, the company's coal mining experience difficulties in meeting their obligations under the contract, shipment of coal to consumers because of an insufficient quantity of empty gondolas and services divisions of Open Joint Stock Company "Russian Railways". In order to cover the growing needs of transportation of coal should be considered infrastructure and modernization of the fuel flows in the whole complex.

In 2013,86 mines with a production capacity of $411,200,000$. Tons, carried coal production of 354 million tons, an increase of $5 \%$ coal production compared with 2012. Coal preparation took place on 59 fabrics, and as a result the amount of enrichment was 139.4 million. Tons, increasing by $11 \%$ the volume of 2012 . This increase in production is due to the fact that in 2013 were put into operation new production capacity and about coal-enrichment plant.

Proposed in this study approach to strategic management of the country's industry include: the establishment of a unified standard in the monitoring, analysis and evaluation of the situation, management decision-making at all levels of corporate and public governance; elimination of dogmatism in the organization of corporate and public governance, encouraging maximum independence and initiative of corporate management in the framework of national development strategies; Schooling management training to all levels of management autonomy, rapid, and therefore efficient and effective management within the company's strategy; creation of a unified and transparent system of monitoring of management decisions and increase the level of responsibility of managers at all levels and branches of government for the implementation of the national strategy, and within it is a strategy of smaller entities (Harpman et al., 2013).

The result of the joint implementation of the proposed principles in the organization of strategic management at different levels of management, should be a combination of freedom in solving economic problems and personal initiative managers. This combination is an absolute competitive advantage of strategic nature, since it increases the flexibility and effectiveness of implemented management decisions and reduces response time, take into account when implementing the strategy of "personal factor" of managers (their ability to identify and realize the hidden potential arising from the specifics of the situation and the prevailing difficult detected with other levels of government). In turn, the proposed strategic approach combines perfectly with competitive advantages in other areas, allowing you to implement a strategic plan and seize the strategic initiative (Popkova \& Tinyakova, 2013b).

Based on the proposed approach, there is a possibility of practical use of the concept of strategic involvement, which considers the enterprise as domestic consumers of services of the state and determines the need to coordinate vectors of enterprises (branches) and the state;

Any action taken as part of the corporate strategy, carried out in conditions of uncertainty and risk, complicated by an independent, masked and difficult to detect policy competition. This situation becomes a constant and inexhaustible source of changes in economic conditions. Various organizational difficulties and resistance competitors further reinforce the uncertainty, reducing to zero forecast accuracy and enhancing the importance of the time factor in the implementation of corporate strategy (Popkova et al., 2013).

Our studies have shown that the head of every industrial enterprise has its own idea of the economic conditions, strategic opportunities and threats, intentions and activities of competitors. It is clear that the administrative decision of each parent's head, on the one hand, must clearly indicate the specific direction of corporate strategy, and on the other - take into account the constant updating of the situation and provide a lower level managers greatest possible freedom in the implementation of the strategy, which, when multiplied by the professionalism and give victory in each situation (Feather et al., 2011). Moreover, the administrative decision of any leader is already outdated at the time of its adoption, because there is a time lag between the identification of "strategic window" of his identity, the development of the program of action within the corporate strategy and its implementation. Corporate strategy adjustments borne by the heads of lower-level management and direct perpetrators and cannot and should not be performed by middle and senior managers. However, the leaders of these levels are responsible not only for the quantity and quality of management decisions, but also for system implementation strategy that includes initiatives of the lower levels of government to implement the strategic plan. In case of violation of the principle of corporate strategy loses its flexibility, it becomes dogmatic, massive and inefficient in a rapidly changing environment fiercely competitive business environment (Hawkins, 2012).

The practical application of this approach to the implementation of corporate strategy involves the following tasks: 
1) establishment of a unified standard in the monitoring, analysis and evaluation of the situation, management decision-making at all levels of corporate and public governance;

2) elimination of dogmatism in the organization of corporate and public governance, encouraging maximum independence and initiative of corporate management in the framework of national development strategies;

3) adaptation of management personnel at all levels of management to independence, rapid, and therefore efficient and effective management within the company's strategy;

4) creation of a unified and transparent system of monitoring of management decisions and increase the level of responsibility of managers at all levels and branches of government for the implementation of the national strategy, and within it - a strategy of smaller entities.

The result of the joint implementation of the proposed principles in the organization of strategic management at different levels of management should be a combination of freedom in solving economic problems and personal initiative managers. This combination is an absolute competitive advantage of strategic nature, since it increases the flexibility and effectiveness of implemented management decisions and reduces response time, take into account when implementing the strategy of "personal factor" of managers (their ability to identify and realize the hidden potential arising from the specifics of the situation and the prevailing difficult detected with other levels of government). In turn, the proposed strategic approach combines perfectly with competitive advantages in other areas, allowing you to implement a strategic plan and seize the strategic initiative (Bergstrom, 2013).

In today's Russian reality becomes relevant "strategic engagement", the essence of which is to develop and effectively implement common to government and business objectives for the real welfare of the whole Russian nation. In this case, there is a need to implement the following management concept:

1) state, represented by the top leaders of the country, responsible for the formulation of national development goals and monitoring their achievement;

2) state, represented by the management structure of the industry of the country, combining its work in the direction of movement of national goals, freedom and initiative in making management decisions, comprehensive responsibility for the results of the industrial sector of the economy;

3) industry, combined with the state common understanding of the situation and development objectives, operating on the same strategic principles and implement corporate social responsibility in the form of job growth, income of their workers and their households, reducing the risk of expectations, increasing confidence in the future.

Current understanding of the strategic situation in relation to national development and industry in particular is completely contrary traditionally in the industrialized countries to the principles of organization management. Ministry of Industry and Energy of the Russian Federation does not have all the necessary powers for the organization of strategic management industry of the country, remaining nominal party and essentially formal observer with no real ability to manage development processes in the industry.

Today, there is a gap between the stated goals of the state (including the growth of national competitiveness) and features the country's industry due to lack of a unified management structure industry (today in the strategic management of industry involved to 89 organizations, each with its own goals and vector development). Representatives of the state actively use their powers for personal purposes that in the absence of a control system of strategic management at the root undermine all the initiatives of industrial enterprises in the area of development.

Industrial enterprises in these conditions have only true way to find a disguise and focus on their plight. To implement the strategic involvement of all active players interested in the development of national industry and achievement through the development of this national goals should coordinate vectors of development, but at this level of strategic involvement of industry in their bulk will be able to develop rapidly, and the state - through their development to solve its strategic goals (Crandall et al., 2012).

Implementation of the strategic involvement in the strategic management of the country's industry is available in the following logical sequence:

\section{Organization of strategic management of the country's industry}

1.1. Creating a structure of strategic management

1.2. Transfer of the strategic management structure appropriate authorization and implementation of activities on the principles of unity of command and responsibility 
2. Organization of strategic engagement at the level of the state and enterprises using the methodology of staff involvement

\subsection{Strategic involvement of civil servants}

\subsection{Strategic involvement of enterprises}

Strategic involvement of employees of the state structure of industrial management and industrial enterprises should be implemented in accordance with the methodology includes the steps of understanding, enthusiasm, sales and retention.

The aim is to determine the stage of understanding the emotional and rational set of promises that could affect the behavior of staff, measures that can engage employees and change their behavior. Real actions at this stage strategic engagement may include: interviews with government and corporate management, leaders of spontaneous groups, workers; audit of state and corporate culture, communication channels, relations workers; collection of real stories from the inner life of the state and industry, management truthfully illustrate the situation (Fisher \& Raucher, 2013).

The aim is to create excitement stage inspiring strategy and action plan, which in turn provides for the development of a hierarchical messages adapted to each level of the hierarchy, the development of a visual interpretation of complex concepts, creation stories and legends that illustrate the basic principles of state and corporate ethics (Randall et al., 2012).

The purpose of the implementation phase should be the conviction and consolidation of key audiences is government and corporate managers. This phase includes the following steps: focus groups, communication activities, campaigns for the development of inclusion (Scott et al., 2012).

The purpose of phase retention is diverting the strategic objectives to operational level, the achievement of fundamental changes in the imperative. By the action of this phase include the establishment of memos, guides and instructions, the nomination for the title of "best", training to improve efficiency, the resulting measurements.

The essence of strategic engagement is reduced to the development and effective implementation of the uniform for the government and business targets for the real growth of the welfare of the whole Russian nation. In this case, there is a need to implement the following management concept: the state represented by the top leaders of the country, responsible for the formulation of national development goals and monitoring their achievement; state on behalf of the management structure of the industry of the country, acting on the basis of unity of command and combines his work in the direction of movement of national goals, freedom and initiative in making management decisions, comprehensive responsibility for the results of the industrial sector of the economy; industrial enterprises, combined with the state common understanding of the situation and development objectives, operating on the same strategic principles and implement corporate social responsibility in the form of job growth, income of their workers and their households, reducing the risk of expectations, increasing confidence in the future (Smith et al., 2011).

\section{Discussion}

Implementation of the strategic involvement in the strategic management of the country's industry is available in the following logical sequence: the organization of strategic management industry of the country (the creation of the structure of strategic management, strategic management structure of the transfer of appropriate powers and carry out activities on the principles of unity of command and responsibility); organization of strategic engagement at the state level and enterprises using the methodology of staff involvement (strategic involvement of civil servants, the strategic involvement of enterprises);

The strategic initiative is crucial, the key to strategic management. Strategic Initiative is a prolonged pressure (impact) to constant accumulation of all the great advantages in the development, building strategic position of competitive advantage - and their subsequent implementation in the transition to a pronounced offensive action in the process.

At the heart of the strategic initiative should be based on a strategic plan with the objective of drastic change in the situation, suitable for its initiator. In this conception may be, for example, the revolutionary changes in technology manufacturing, massive introduction of new materials, active development and the sudden introduction of new forms of non-price competition, the introduction on the background of basic solutions of new methods of management in the conditions of risk and uncertainty, etc. Strategic plan usually not on the 
surface and requires a deep study of the situation permits increased risk, in most cases based on the use of heuristics and intuitive justification and decision making.

The strategic plan calls for multivariate calculations looking at a number of periods (moves) forward, with maximum regard for the element of surprise competitors sector or region, and operational impact on the evolving financial and economic situation. Strategic plan and strategic initiative is to bring effective strategic management only if the resources to ensure proper maneuverability and a sufficient number of strategic reserves for this purpose.

Strategic management, in our view, should, in the end, be reflected in the establishment for the purpose of targeted strategic guidance and target strategic guidelines.

Target strategic guidelines logical are to take the specific characteristics of the general goals and objectives of all other levels of economic entities at the national and regional stages of management.

In turn, the target can be considered strategic regulations quantitative digital assignments, the achievement of which is a phased approach to target strategic targets of economic development projects.

In this connection, put forward by the President of the Russian Federation, the national idea - the creation of a competitive economy in the country is possible, in accordance with the above, consider a classic example of targeted strategic guidelines, and they also put forward the goal of doubling in 10 years, the gross domestic product (GDP) of the sample target strategic norm.

Applying this approach to the organization of strategic management makes it possible to implement the concept of "strategic engagement", which considers the enterprise as domestic consumers of services of the state and determines the need to coordinate vectors of enterprises (branches) and the state.

\section{Conclusion}

At present, the development of coal mining industry cannot be done without the scientific, technical and innovation policy pillars of which are:

- Improving the technical equipment of coal production, including the use of high-performance enterprises of mining and transport equipment cyclic and continuous;

- The use of cyclic-flow and flow technology, the organization of aid in the further development of coal mining technology using mainly in long term mechanized complexes latest technical level, as well as innovative technology using continuous miners and self-propelled means of transportation and marketing of coal;

- The application of measures to improve the quality of coal products;

- Development and implementation of efficient technologies of coal preparation;

- The use of the latest technology of commercial production of coal mine methane;

- Improvement of technologies for industrial production of liquid products deep processing of coal;

- Development of new technologies and equipment for effective de-gassing coal seams.

In the near future in order to achieve long-term development of coal mining enterprises must carry out a number of priority actions:

1) To approve the legislative program licensing coal deposits for the period up to 2015 ;

2) Introduce legislative norms, which would provide for the formation of coal mines on a single integrated system for managing the security industry and the protection of workers;

3) Create a new version of the rules of safety in coal mines, with subsequent approval, and to improve safety standards and rules of industry, aimed at reaction adequate fire protection shafts, dust and gas regime, as well as willingness to mine accidents.

Also necessary is to improve the conditions of competition coal markets. And mostly what is supposed to pay attention is to prevent the negative impact of the price of local and regional coal monopoly and further unjustified growth in coal prices under the influence of price transformations in the field of gas. This is to ensure economic preferences coal consumption compared to the alternatives. Thus, we can conclude that the coal industry plays an important role in the economy of the country and has a great potential in coal mining.

\section{References}

Bergstrom, J. C. (2013, September). Benefits \& Costs Transfer in Natural Resource Planning. University of Georgia, Department of Agriculture and Applied Economics. 
Crandall, K., Colby, B., \& Rait, K. (2012). Valuing Riparian Areas: A Southwestern Case Study. Rivers, 3(2), 88-89.

Feather, P., Hellerstein, D., \& Hansen, L. (2011, April). Economic Valuation of Environmental Benefits and the Targeting of Conservation Programs, The Case of the CRP. USDA, Agricultural Economic Report (No. 778).

Fisher, A., \& Raucher, R. (2013). Intrinsic Benefits of Improved Water Quality: Conceptual and Ethical Perspectives. Advances in Applied Micro-Economics, 3, 37-66.

Harpman, D. A. et al. (2013). Nonuse Economic Value: Emerging Policy Analysis Tool. Rivers, 4(4), 280-291.

Hawkins, J. W. (2012). Characterization and Effectiveness of Remining Abandoned Coal Mines in Pennsylvania. Report of Investigations (RI 9562) prepared for Bureau of Mines, United States Department of Interior.

Popkova, E. G., \& Tinyakova, V. I. (2013a). New Quality of Economic Growth at the Present Stage of Development of the World Economy. World Applied Sciences Journal, 5, 617-622.

Popkova, E. G., \& Tinyakova, V. I. (2013b). Drivers and Contradictions of Formation of New Quality of Economic Growth. Middle-East Journal of Scientific Research, 11, 1635-1640.

Popkova, E. G., Morkovina, S. S., Patsyuk, E. V., Panyavina, E. A., \& Popov, E. V. (2013). Marketing Strategy of Overcoming of Lag in Development of Economic Systems. World Applied Sciences Journal, 5, 591-595.

Randall, A., Grunewald, O., Johnson, S., Ausness, R., \& Pagoulatos, A. (2012). Reclaiming Coal Surface Mines in Central Appalachia: A Case Study of Costs and Benefits. Land Economics, 54(4), November.

Scott, M., Bilyard, G. R., Link, S. O., Ulibarri, C. A., Westerdahl, H., Ricci, P. F., \& Seely, H. E. (2012). Valuation of Ecological Resources and Functions. Environmental Management, 22(1), 49-68. http://dx.doi.org/10.1007/s002679900083

Smith, S., \& Bridger, J. (2011). Socioeconomic Impacts of Mine Reclamation Projects, Broad Top Township. Final Report to the Western Pennsylvania Coalition for Abandoned Mine Reclamation.

\section{Copyrights}

Copyright for this article is retained by the author(s), with first publication rights granted to the journal.

This is an open-access article distributed under the terms and conditions of the Creative Commons Attribution license (http://creativecommons.org/licenses/by/3.0/). 